\title{
STOCK MARKET CRASH: A COMPARATIVE ANALYSIS BETWEEN SUB-PRIME CRISIS AND COVID-19
}

\author{
Shivam Tripathi \\ Job Trainee, \\ Gujarat University.
}

\author{
Ashutosh Chaubey \\ P.G. Student, \\ S.D. School of Commerce, Gujarat University.
}

Article DOI: https://doi.org/10.36713/epra4715

\begin{abstract}
The Covid-19 pandemic and Sub-Prime Crisis are major incidents that happened to the world in almost 13 years. The stock market crashed to the new heights during both incidents. The study made here on five global stock indices represents the intensity of fall and the correlation between the indices globally. The intensity was greater for the Covid-19 pandemic phase but the returns on an average tanked more in Sub-Prime Crisis. The stock indices were all positively correlated showing the simultaneous change occurring throughout the globe while the ANOVA showed that the average returns were not different from each other for all five indices confirming the coordinated movements.
\end{abstract}

KEYWORD: Stock Market Crash, Covid-19, Sub-Prime Crisis, Stock Indices, ANOVA

\section{INTRODUCTION}

The Sub-Prime Crisis was a major incident in the U.S. economy from 2007 to 2010 . The crisis led to severe consequences for the economy which came to be known as the Great Recession afterwards. During the period of mid-2006, the house prices in the U.S. declined to a great extent which led to a rise in interest rates of mortgage adjusted securities. The rise caused higher monthly payments leading to default situations for many borrowers at large. This finally made the Housing bubble burst as the institutions collapsed one after the other due to a shortage of funds to operate and pay their dues. The investors globally were affected because of this and a massive fall in investment was witnessed. The crisis had affected most in the U.S. and the European region. According to a report, the U.S. Stock Market fell more than 50\% during 2006-2009. The country faced unemployment which came back to normal during 2014. The U.S. economy received bailout packages worth 626 billion \$ which got recovered by 2018. The European region was also inflicted with heavy losses. ${ }^{1}$

The Covid-19 is a name given to the new coronavirus disease by the World Health Organization

\footnotetext{
${ }^{1}$ https://www.wikipedia.org/
}

which was first detected in Wuhan city of China in December 2019. The disease is a pneumonia type contagious in nature. After the unstoppable force of the novel virus was witnessed it became a global emergency in no time. The disease has spread to every continent now as of mid-2020 apart from Antarctica. The disease is not only a health issue for the various countries but also a reason for social, political, and economic crisis which may lead to a long-term economic deficit. The only way of not getting affected by the virus at the initial stage was solidarity, hence, lockdowns in many countries were imposed. This led to unemployment and massive losses in business units. According to the International Labor Organization around 195 million jobs could have been lost worldwide and the number is still increasing. Thousands of lives have been lost worldwide and millions have been affected. This has resulted in it becoming a situation of the highest challenge after World War II according to the United Nations Development Program. ${ }^{2}$

A study, hence, becomes essential to know which out of the two given phases had more drastic effects on the indices worldwide as it would reflect the

\footnotetext{
${ }^{2}$ https://www.who.int/, https://www.undp.org/
} 
overall economy too, in a specific manner.

\section{LITERATURE REVIEW}

Castellanos, A. M. et. al (2011) found that NYSE movements exerted a great influence, during the first two working days, in a limited group of countries such as Mexico, Chile, Peru, Canada, Germany, Hong Kong, Czech Republic, and Austria. After eight working days, it is observed that 21 stock exchanges (see the map of the world) were significantly affected. The most important concluding remark is that the stock market is synchronized all over the world in an approximated period of two months. They used the Pearson parameter for their research.

A Shirvani (2020) studied the bivariate kinematic time series for the 11 years of daily price return and roughness for the S\&P 500 index and found that the probability distributions exhibit a significant negative skewness relative to that of a normal distribution that might be attributed to the effect of long memory in the time series. The long memory effect of the stock market crash of 2008 is featured by that the number of degrees of freedom in the empirically observed distributions fell while the tail coefficient of the joint distribution increased after the crash, indicating the presence of a heavy-tail in distributions traditionally attributed to the effect of long memory in the time series. These results significantly feature the long memory effect of the crash. The researcher examines the dependence structure of return and roughness using stock market data and asymmetric copula method. Research purposes were expanded to meet the primary objective of this study, and results were derived through a proper procedure to reach the conclusions. The author has identified a few limitations, and he has given three suggestions for future researchers to overcome those limitations. The study was conducted for S\&P 500 stock price data, so the results can be generalized for other indices, especially for Real Estate indices.

D McMinn (2020) found the Decennial Cycle which suggested that a major market decline and the US recession were distinctly possible in the year 2020 (McMinn, 2020). A DJIA bear market commenced on February 12 and a severe world recession is now highly likely.

D Zhang et. al (2020) provides a simple but original statistical analysis of the impact of the COVID-19 pandemic on stock market risk. The virus has already claimed thousands of lives and brought significant challenges to countries from all over the world. The financial markets have seen dramatic movement on an unprecedented scale. The present results show that global financial market risks have increased substantially in response to the pandemic. Individual stock market reactions are linked to the severity of the outbreak in each country. The great uncertainty of the pandemic and its associated economic losses has caused markets to become highly volatile and unpredictable.

\section{OBJECTIVE OF STUDY}

The Comparative Assessment utilizes various statistical tools and techniques for the analysis. This study aims at using them to reach a certain conclusion. The primary aim of this study is to determine or ascertain which phase-out of the two given had a larger effect during the given interval. Various other objectives of the study are listed below:

- To compare the performance of stock indices during the two periods.

- To analyze the intensity of fall between the two phases and compare them.

- To determine the most efficient stock index in comparison to the former crisis.

- To determine the most affected stock index in the Pandemic phase.

- To help investors and others overview the extent of fall comparatively.

- To analyze the volatilities in comparison to the previous crash.

- To ascertain whether any index performed differently from others.

\section{RESEARCH METHODOLOGY}

The study is based on secondary data available from the data source Yahoo Finance ${ }^{3}$. The data includes the daily Adjusted Close of the stock indices from different countries. The population could be stated as all the stock indices globally but for the research purpose a sample of 5 stock indices has been chosen, each from a different country. The following stock indices have been worked upon: S\&P 500, BSE Sensex, German DAX, NIKKEI, and Hang Seng. The following tools were used for analyzing the data: -

a) Mean: A measure to determine the average of data.

b) Variance: A measure to determine variations.

c) Standard Deviation/Volatility: A measure to determine deviations from the mean in the unit same as the data availed.

d) Correlation: A measure representing the degree and direction of the relationship between two variables.

e) One-way ANOVA: A statistical test which checks the equality of means between two or more than two groups.

\footnotetext{
${ }^{3}$ https://in.finance.yahoo.com/
} 
Following hypothesis was formulated for the test: H0: There is no significant difference between the mean returns of five stock indices in the given period. H1: There is a significant difference between the mean returns of stock indices in the given period.

\section{DATA ANALYSIS AND INTERPRETATION}

The comparative assessment of the same set of stock indices from 5 different countries was analyzed statistically for six months taken from the Sub-Prime Crisis of 2007-2010 and Covid-19 Pandemic 20192020. The duration of six months was selected such that the bottom during both the periods would have touched in the fifth or sixth month in analysis making the data more appropriate for comparison.

The software used for collecting the data was Python
2.7 and the source being Yahoo Finance. Prices availed were of Adjusted Close nature for all the indices allowing for more precision in analysis. The number of observations availed on daily basis ranged from 115125 for each index. Tickers were used for availing the data from the source, hence, a brief introduction about the tickers is given below: -

${ }^{\wedge} \mathrm{GSPC}=\mathrm{S} \& \mathrm{P} 500$ (the stock index from the U.S. covering 500 major companies)

${ }^{\wedge} \mathrm{BSESN}=\mathrm{BSE}$ Sensex (the stock index from India covering 30 major companies)

${ }^{\wedge} \mathrm{N} 225=$ NIKKEI (the stock index from Japan covering 225 major companies)

${ }^{\wedge} \mathrm{GDAXI}=\mathrm{DAX}$ (the stock index from Germany covering 30 major companies)

${ }^{\wedge}$ HSI $=$ Hang Seng (the stock index from Hong Kong covering 50 major constituents)

\subsection{SIMPLE RETURNS GRAPH (NORMALIZATION TO 100 WITH BASE = DAY 1): -}

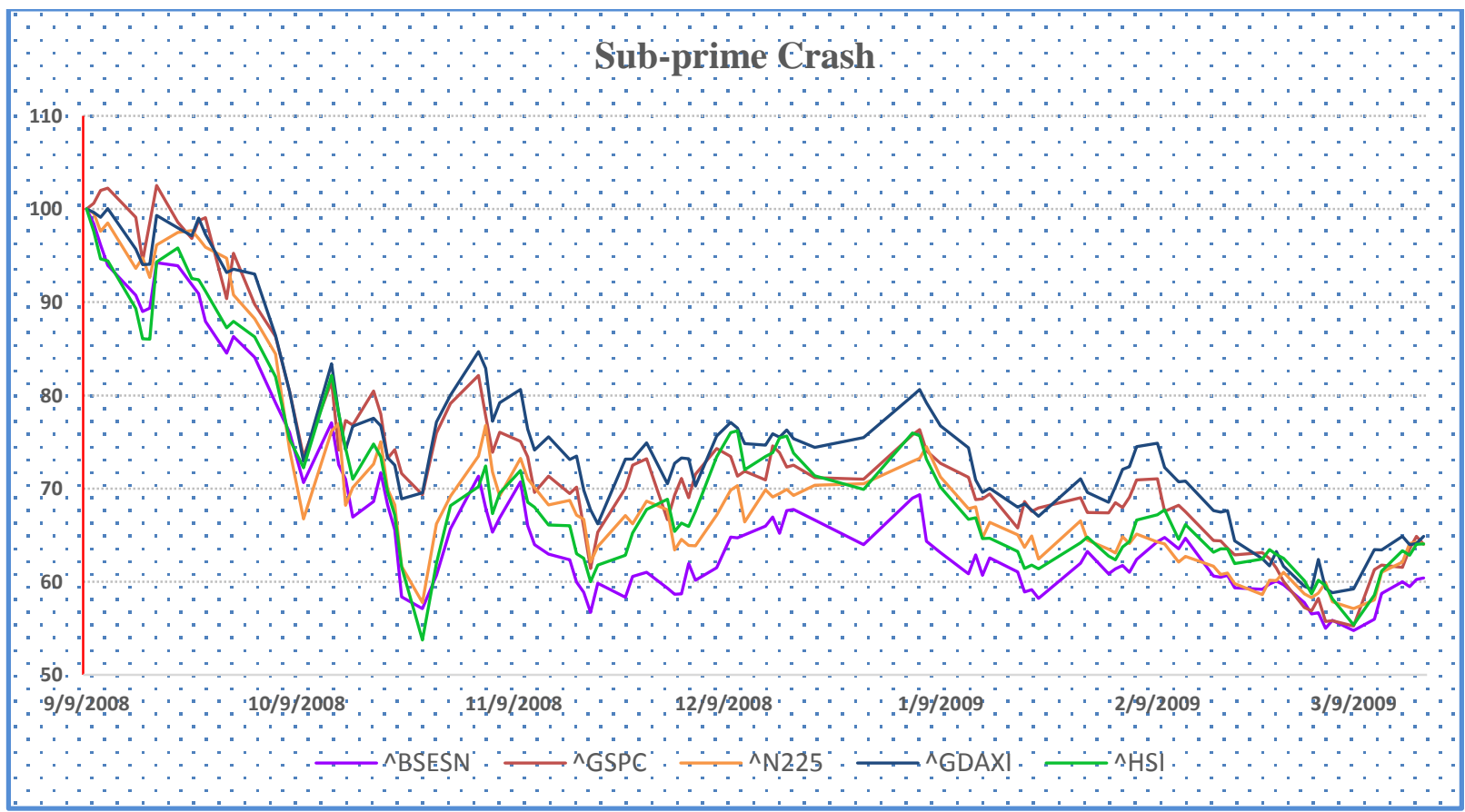




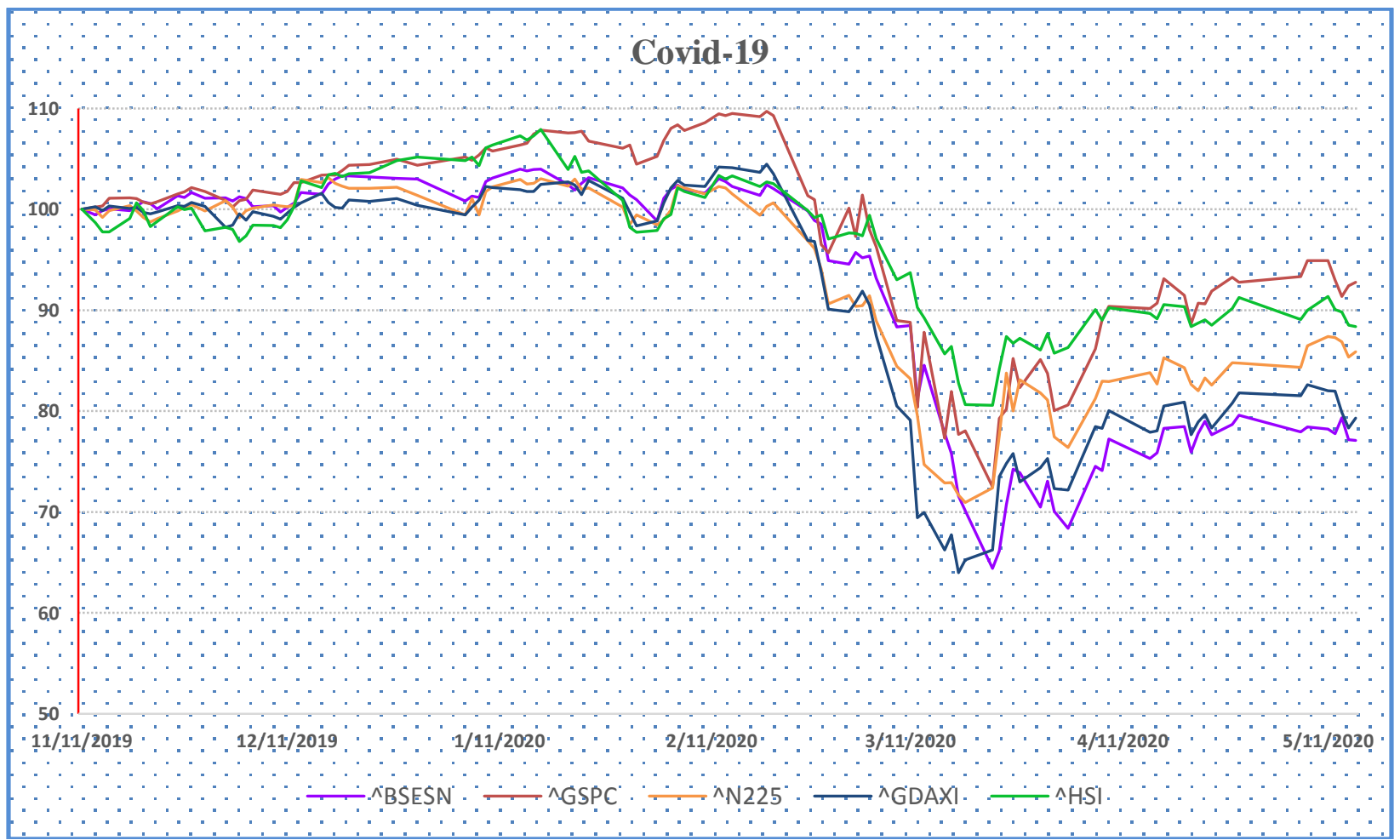

The graphs above have been obtained from Python 2.7 and are based on [Adjusted Close/Adjusted Close(base) * 100] keeping the first day of the six months as a constant base for each calculation. It can be seen from the first graph i.e., the Sub-prime crash that the returns fell on a relatively lower yet constant pace than the Covid-19 crash during these six months but the fall was greater than the latter as the bottom fell below 60 in the former one. The Covid-19 crash depicts a sudden and major decline during the March and April months of 2020. This can be viewed because of growing fear in the minds of investors due to the non-availability of any medicines which can stop the pandemic to occur and the rising cases on an exponential form leading to deaths. The graph of Sub-prime crisis hits low in October-November as well as March months of 2008 and 2009 respectively which was the result of several FIs collapsing. Considering the graphs, it can be seen that Hang Seng which fell the most during 2008-09, held strong in the Covid-19 period, whereas, the German Dax which was least affected out of the five during Sub-prime crash has been among one of the most affected ones in the pandemic. The massive fall of German Dax during the second phase can be related to the outburst of Coronavirus cases in Europe on the highest scale at initial stages. The rest of the indices have also shown a fall in both cases depicting a positive correlation among them.

\subsection{MEANS AND VARIANCES}

\begin{tabular}{|c|c|c|c|}
\hline \multicolumn{4}{|c|}{ Daily Log Returns (Mean Values) } \\
\hline \multicolumn{2}{|c|}{ Sub-Prime } & \multicolumn{2}{|c|}{ Covid-19 } \\
\hline${ }^{\wedge} \mathrm{BSESN}$ & $-0.4096 \%$ & ${ }^{\wedge} \mathrm{BSESN}$ & $-0.2099 \%$ \\
\hline${ }^{\wedge} \mathrm{GSPC}$ & $-0.3041 \%$ & $\wedge^{\wedge} \mathrm{GSPC}$ & $-0.0555 \%$ \\
\hline$\wedge$ N225 & $-0.5533 \%$ & ${ }^{\wedge} \mathrm{N} 225$ & $-0.1178 \%$ \\
\hline$\wedge^{\wedge} \mathrm{GDAXI}$ & $-0.4001 \%$ & $\wedge^{\wedge} \mathrm{GDAXI}$ & $-0.1861 \%$ \\
\hline${ }^{\wedge} \mathrm{HSI}$ & $-0.3213 \%$ & ${ }^{\wedge} \mathrm{HSI}$ & $-0.0510 \%$ \\
\hline
\end{tabular}

The mean values shown above are based on log return values obtained from Python 2.7 of both the periods daily. Both the tables show that the indices have generated negative returns on a daily average. The percentage fall of Nikkei was highest on an average during the former six months, whereas, in the pandemic phase the six months have shown that Sensex fell the most out of these five. The reason why the former is showing higher values can be related to the constant fall which occurred throughout the six months while in the latter, there was a sudden major fall in a single month gap and the previous months not being so major 
which lead to an averaging effect of lower falls comparatively. A month-only comparison might have shown a different result from what can be seen here due to the massive fall as depicted from the graphs previously.

\begin{tabular}{|l|l|l|l|}
\hline \multicolumn{5}{|c|}{ Variances (in squared \%) } \\
\hline \multicolumn{2}{|c|}{ Sub-Prime } & \multicolumn{1}{c|}{ Covid-19 } \\
\hline${ }^{\wedge} \mathrm{BSESN}$ & 10.72 & ${ }^{\wedge} \mathrm{BSESN}$ & 6.88 \\
\hline${ }^{\wedge} \mathrm{GSPC}$ & 13.66 & ${ }^{\wedge} \mathrm{GSPC}$ & 7.78 \\
\hline${ }^{\wedge} \mathrm{N} 225$ & 14.20 & ${ }^{\wedge} \mathrm{N} 225$ & 4.15 \\
\hline${ }^{\wedge} \mathrm{GDAXI}$ & 11.56 & ${ }^{\wedge} \mathrm{GDAXI}$ & 6.53 \\
\hline${ }^{\wedge} \mathrm{HSI}$ & 15.12 & ${ }^{\wedge} \mathrm{HSI}$ & 2.76 \\
\hline
\end{tabular}

The above-given tables show the variances of five stock indices over the two phases. The data makes it clear that variances were higher for all the indices during the six months of the sub-prime crash. The interesting thing to note is that Hang Seng which had the highest variance during the first phase has shown the least variance during the second phase, ultimately, leading to confirmation of graphs availed. While the German Dax which had a low variance among the group formerly is showing a little bit high comparatively during the pandemic phase.

\subsection{VOLATILITIES/STANDARD DEVIATIONS}

\begin{tabular}{|c|c|c|c|}
\hline \multicolumn{4}{|c|}{ Daily Standard Deviations } \\
\hline \multicolumn{2}{|c|}{ Sub-Prime } & \multicolumn{2}{|c|}{ Covid-19 } \\
\hline${ }^{\wedge} \mathrm{BSESN}$ & $3.2745 \%$ & ${ }^{\wedge} \mathrm{BSESN}$ & $2.6226 \%$ \\
\hline$\wedge^{\wedge} \mathrm{GSPC}$ & $3.6963 \%$ & $\wedge^{\wedge} \mathrm{GSPC}$ & $2.7896 \%$ \\
\hline${ }^{\wedge} \mathrm{N} 225$ & $3.7678 \%$ & ${ }^{\wedge} \mathrm{N} 225$ & $2.0384 \%$ \\
\hline${ }^{\wedge} \mathrm{GDAXI}$ & $3.3997 \%$ & ${ }^{\wedge} \mathrm{GDAXI}$ & $2.5560 \%$ \\
\hline${ }^{\wedge} \mathrm{HSI}$ & $3.8889 \%$ & ${ }^{\wedge} \mathrm{HSI}$ & $1.6623 \%$ \\
\hline
\end{tabular}

The standard deviations, commonly known as volatilities have been obtained on the similar log return values from the observed data as before. These deviations are representing the average daily volatility in stocks. From the data availed, deviations occurred on a greater scale for the prior six months period. This might be due to the constant fall occurring in the prior one for months continuously due to one or the other incidents happening. For the latter one, the sudden ups and downs occurred for a relatively shorter period than the prior one, hence, averaging may have affected the results. The data shows that Hang Seng which was having the highest volatility during the Sub-prime
Crisis has the least volatility during the Covid-19 outbreak. The reason might be the low effects of Coronavirus in Hong Kong, still, the effects of globalization is inherent and thus, fall sentiments can be observed with negative means and high volatilities availed. The S\&P 500 which includes the top 500 companies from the U.S. has shown considerable volatility in both the scenarios, as, in the latter period the volatility is highest which might have resulted from the fear emerging in the minds of investors due to uprising cases of the novel disease with no cure still in hand.

\subsection{CORRELATION ANALYSIS}

The Correlation Co-efficient has been among the major tools for determining the degree and direction of the relationship between two variables. The data below shows the Correlation matrix obtained using Python 2.7 between the five stock indices in both the six months.

There is no single negative number obtained showing that all the stock indices move in the same direction up to a certain degree. Following output was obtained when the test was run: - 


\begin{tabular}{|c|c|c|c|c|c|c|c|c|c|c|c|}
\hline \multicolumn{12}{|c|}{ Correlation Output } \\
\hline \multicolumn{6}{|c|}{ Sub-Prime } & \multicolumn{6}{|c|}{ Covid-19 } \\
\hline & ${ }^{\wedge}$ BSESN & ${ }^{\wedge} \mathrm{GSPC}$ & ${ }^{\wedge} \mathrm{N} 225$ & ${ }^{\wedge}$ GDAXI & ${ }^{\wedge} \mathrm{HSI}$ & & ${ }^{\wedge} \mathrm{BSESN}$ & ${ }^{\wedge} \mathrm{GSPC}$ & ${ }^{\wedge} \mathrm{N} 225$ & ${ }^{\wedge}$ GDAXI & ${ }^{\wedge} \mathrm{HSI}$ \\
\hline ^BSESN & 1.000000 & 0.516038 & 0.550308 & 0.599716 & 0.719967 & ${ }^{\wedge} \mathrm{BSESN}$ & 1.000000 & 0.535216 & 0.526381 & 0.650548 & 0.747711 \\
\hline${ }^{\wedge}$ GSPC & 0.516038 & 1.000000 & 0.275135 & 0.718153 & 0.504353 & ${ }^{\wedge}$ GSPC & 0.535216 & 1.000000 & 0.357336 & 0.763153 & 0.457538 \\
\hline${ }^{\wedge} \mathrm{N} 225$ & 0.550308 & 0.275135 & 1.000000 & 0.563615 & 0.734242 & ^^225 & 0.526381 & 0.357336 & 1.000000 & 0.609727 & 0.749384 \\
\hline ^GDAXI & 0.599716 & 0.718153 & 0.563615 & 1.000000 & 0.579209 & ${ }^{\wedge}$ GDAXI & 0.650548 & 0.763153 & 0.609727 & 1.000000 & 0.672642 \\
\hline $\begin{array}{l}{ }^{\wedge} \mathrm{HSI} \\
\end{array}$ & 0.719967 & 0.504353 & 0.734242 & 0.579209 & 1.000000 & $\begin{array}{l}{ }^{\wedge} \mathrm{HSI} \\
\end{array}$ & 0.747711 & 0.457538 & 0.749384 & 0.672642 & 1.000000 \\
\hline
\end{tabular}

The correlation data shown above in both the quadrants is positive which means that there is a simultaneous and similar increase to an extent in one index with an increase in the other one and vice versa. During the Sub-prime Crisis, the highest correlation is observed between Nikkei and Hang Seng, which is 0.734242, a moderately strong correlation. While the least correlation is observed between the S\&P 500 and Nikkei, which is 0.275135 , weak correlation. The stock indices BSE Sensex and Hang Seng as well as German Dax and S\&P 500 are also showing a moderately strong correlation while all other pairs have moderate correlations. In the pandemic phase, the data shows that there is a moderately strong correlation between Hang Seng and Nikkei as well as Hang Seng and BSE Sensex just like the previous crisis period. A significant change can be observed that the German Dax and S\&P 500 have the highest correlation in the pandemic phase which can be a result of Europe and the United States getting affected the most in initial stages due to the novel virus. From a bird's eye view of both the tables, it can be said that the correlation between the global stock indices has increased during the decade due to the effects of increasing acceptance of globalization policies and increasing technological trade and developments.

\subsection{ONE-WAY ANOVA}

\begin{tabular}{|c|c|}
\hline \multicolumn{2}{|c|}{ One- way ANOVA } \\
\hline Sub-prime & Covid-19 \\
\hline 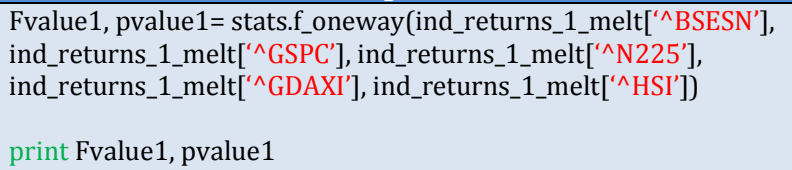 & 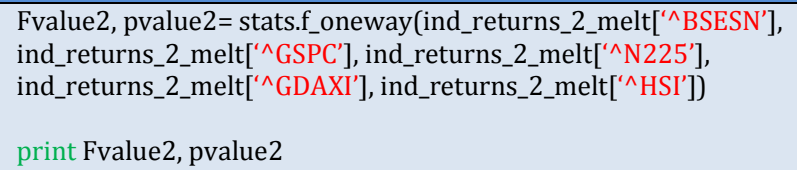 \\
\hline $\begin{array}{l}\text { F-value }=0.05504430039128091, \quad \text { p-value } \\
0.994345460375282\end{array}$ & $\begin{array}{l}\text { F-value }=0.1063341122902684, \\
0.9802872796400264\end{array}$ \\
\hline
\end{tabular}

ANOVA is used for testing the equality of means when there are two or more than two groups and is a popular measure around the world used for Financial, Statistical, and many other types of studies. The standard One-way ANOVA is used here for testing purposes, conducted through Stats Module of Scipy Package in Python 2.7. The test was conducted on 92 observations in each variable out of approximately 120 observations availed in each. The difference is due to the problem of missing observations for which the whole row of observations was dropped out for the test. The data from both the tables show that the $\mathrm{p}$-value is greater than 0.05 (which is a default value in such tests). This makes it clear that we fail to reject the null hypothesis and thus, there exists no significant difference between the mean values in both the phases. The F-values also is less than the table values, therefore, indicating the failure of rejection for the null hypothesis. Concluding the results, it can be said that no two groups are different from each other which should also not mean that the groups are the same completely.

\section{SUGGESTIONS}

The study incorporated six months only which can be extended for further studies and more generalizable results. The selection of bases has been made randomly which can be more precise if based on some relevant event or impulse. The assumptions of ANOVA test like Homogeneity of Variance and Normality check could be done by using other tests like Bartlett's/Levene's Test and Shapiro Wilks Test respectively. The study is based on only five indices while many other such indices can still be used to obtain further precision. The factors resulting in such results can be further studied to get an in-depth view of both the scenarios. The result here is obtained in specificity and thus, shouldn't be generalized for parameters different from the one used above

\section{CONCLUSION}

The study showed that the stock indices have generated negative returns on an average leading to an overall negative or bearish trend. The data availed from Graph and Correlation Matrix have helped in 
deciphering the similar movements in stock indices globally. All the stock indices have been affected globally to some extent due to the change in one or two. Behavioral finance is also working here, as, it is seen highly in existence during the pandemic phase. Graphs showed how drastic fall occurs when people are uncertain in recent times due to the increase in transparency, technological development, and education. The constant decrease in stock indices shows how the money flew out from the investment zone whether be it domestic investors or foreign ones. The ANOVA helped in determining that groups or indices had no significant differences between them leading to a conclusion that all indices have moved in tandem due to the increased effect of globalization.

Both periods of Crisis have shown similar results up to a certain extent though not completely the same. The Sub-prime Crisis had a more constant fall occurring on a daily basis while the Covid-19 Crisis witnessed a sudden massive fall for one month. The average daily fall during the half-year period was also high during the former one. The index Hang Seng has shown the biggest change during the decade as it has sustained relatively better during the latter phase. On the other hand, the most tragically affected index was Dax during the assessment which performed considerably better in the former crisis but was beaten up in the latter one. To conclude it can be said that the Pandemic had an adverse effect on stock indices globally on a larger scale and the induced lockdown due to unstoppable novel virus may lead to much worse results in upcoming periods but for the critical six months duration under study we can see that the Subprime Crash had a greater effect on the indices as a whole for the period under consideration.

\section{REFERENCES}

1. Castellanos, A. M. (2020). The contagion from the 2007-09 US stock market crash. International Journal of Banking and Finance, 8(4), 67-81.

2. Shirvani, A. (2020). Stock returns and roughness extreme variations: A new model for monitoring 2008 market crash and 2015 flash crash. Applied Economics and Finance, 7(3), 78-95.

3. McMinn, D. (2020). The crash of 2020. Research Gate [2020]. Disponible en: Acceso en, 23(04).

4. Zhang, D., Hu, M., \& Ji, Q. (2020). Financial markets under the global pandemic of COVID19. Finance Research Letters, 101528. 